\title{
Increased immunoexpression of trefoil factors in salivary gland tumors
}

Ponlatham Chaiyarit ${ }^{1,2}$; Poramaporn Klanrit ${ }^{1,2}$; Pensri Photipakdee ${ }^{1,2}$; Ajiravudh

Subarnbhesaj ${ }^{1,2}$; Andrew S. Giraud ${ }^{3}$

${ }^{1}$ Department of Oral Diagnosis, Faculty of Dentistry, Khon Kaen University, Khon Kaen 40002, Thailand

${ }^{2}$ Research group of chronic inflammatory oral diseases and systemic diseases associated with oral health, Khon Kaen University, Khon Kaen 40002, Thailand

${ }^{3}$ Murdoch Childrens Research Institute, The Royal Children's Hospital

Flemington Road Parkville, Victoria 3052, Australia

\section{Short running title:}

Trefoil factors in patients with salivary gland tumors

\section{Corresponding author}

Associate Professor Ponlatham Chaiyarit

Department of Oral Diagnosis

Faculty of Dentistry, Khon Kaen University

Khon Kaen 40002

Thailand

Tel: +6643202405 ext 11154

Fax: +6643202862

E-mail: cponla@kku.ac.th 


\section{Abstract}

Objective:

Very little is known about the role of trefoil factors (TFFs) in salivary gland tumors, and TFF immunoexpression has never been investigated in such tumors. The aim of this study was to evaluate TFF immunoexpression in benign and malignant salivary gland tumors.

Materials and Methods:

Benign ( $\mathrm{n}=25)$ and malignant $(\mathrm{n}=25)$ salivary gland tumor specimens were included in this study, using mucocele $(\mathrm{n}=25)$ specimens as a control group. Immunohistochemical staining was performed to evaluate the expression of TFFs (TFF1, TFF2, and TFF3) by semiquantitative means.

Results:

Expression of TFF1, TFF2 and TFF3 were significantly increased in benign ( $\mathrm{p}=0.001$; $\mathrm{p}=0.005 ; \mathrm{p}<0.001$, respectively) and malignant $(\mathrm{p}<0.001 ; \mathrm{p}<0.001 ; \mathrm{p}<0.001$, respectively $)$ groups as compared with the control group. Patterns of co-expression between TFF1/TFF2; TFF2/TFF3; and TFF1/TFF3 were different among the three groups.

\section{Conclusions:}

The present study provided new information showing that all TFFs were significantly increased in benign and malignant salivary gland tumors, and overexpression of TFFs could be associated with neoplastic transformation in salivary gland tissues.

Clinical Relevance:

Overexpression of TFFs may be useful as biomarkers in terms of differential diagnosis between salivary gland tumors and other oral neoplasms for which clinical manifestations are indistinguishable.

Keywords: immunohistochemistry; salivary gland tumor; trefoil factor 


\section{Introduction}

Trefoil factors (TFFs) are secreted molecules mainly synthesized by mucin-producing epithelial cells and which constitute a family of short peptides with disulfide bonds that form a three leafed structure, also called a trefoil domain [1, 2]. Human TFFs consist of three members, TFF1, TFF2, and TFF3. TFF1 and TFF3 contain one trefoil domain, whereas TFF2 contains two trefoil domains. TFF1 and TFF3 may form dimers through a cysteine residue located near the C-terminus $[1,2]$. TFFs are expressed in various human tissues and secretions $[3,4]$. TFFs have been implicated in several biological functions such as cytoprotection and wound healing [1,2]. Regarding oral compartments, salivary glands are the predominant site of TFF synthesis, with some contribution from goblet cells of the parotid ducts and oral epithelia [5-10]. There is a paucity of data demonstrating the functions and mechanism of TFFs in oral compartments. It was reported that TFF3 was a modifying factor for signaling pathways involved in cell survival, cell proliferation, and cell migration of oral keratinocytes $[11,12]$. Therefore, the expression of TFF peptides in saliva and oral epithelia may be an essential factor in protection against oral mucosal tissue damage.

Besides the protective role of TFFs in mucosal tissues, it has been reported that TFFs have pleiotrophic actions in tumorigenesis [13]. It is evident that TFFs have contradictory roles as tumor suppression and tumor progression factors, likely dependent on the site of expression [14]. Altered expression of TFFs in human solid cancers such as stomach, breast, colon, and prostate cancers has been reported with loss of TFF1 and 2 in the stomach, and generally increased expression of most TFF in the latter epithelia with neoplastic progression [14-17]. Although compelling evidence from experimental and clinical studies indicates a strong association between TFFs and human cancers, very little is known about the role of TFFs in oral cancers. Our previous study demonstrated that TFF2 and TFF3 expression was significantly decreased in oral squamous cell carcinoma (OSCC) [18]. These findings suggest 
a possible tumor suppressive role of TFF2 and TFF3 in OSCC. However, the involvement of TFFs in other related tumors of the oral cavity such as salivary gland tumors has never been identified.

Salivary gland tumors are relatively uncommon, and demonstrate a wide range of cell types and morphological diversity. The majority of salivary gland tumors are epithelial in origin [19]. The incidence of salivary gland tumors was reported to range from 0.4 to 13.5 cases/100,000 population per year [20]. Pleomorphic adenoma is common as benign salivary gland tumors, whereas mucoepidermoid carcinoma and adenoid cystic carcinoma are common as malignant salivary gland tumors [19]. Similar morphologic features between salivary and mammary gland tumors such as mucoepidermoid carcinoma, adenoid cystic carcinoma, and basal cell adenocarcinoma have been reported [21-23]. Moreover, previous studies demonstrated the involvement of $T F F 1$ and $T F F 3$ genes in mammary gland tumors, and these two genes were used as biomarkers for detecting disseminated malignant cells of breast cancer [24-26]. By analogy, it can be hypothesized that TFFs might also contribute to salivary gland tumor development. Therefore, the aim of the present study was to determine TFF expression patterns in benign and malignant salivary gland tumors, using an immunohistochemical staining method.

\section{Materials and Methods}

\section{Tissue specimens}

There were 75 formalin-fixed and paraffin-embedded biopsy specimens in this study. All specimens were retrieved from the archives of Division of Oral Pathology, Department of Oral Diagnosis, Faculty of Dentistry, Khon Kaen University, Thailand. The specimens of the control group $(n=25)$ were diagnosed as mucocele, those of which contain groups of normal minor salivary glands. According to WHO classification of salivary gland tumors [27], the specimens of the benign group were diagnosed as pleomorphic adenoma $(n=25)$. The 
specimens of the malignant group were diagnosed as mucoepidermoid carcinoma $(n=11)$; adenoid cystic carcinoma $(n=6)$; polymorphous low-grade adenocarcinoma $(n=4)$; acinic cell carcinoma $(n=3)$; and basal cell adenocarcinoma $(n=1)$. The approval of the ethical committee for the use of human subjects, Khon Kaen University (HE542281) was obtained. Immunohistochemical study

Consecutive sections of formalin-fixed and paraffin-embedded biopsy specimens were cut ( $5 \mu \mathrm{m}$ thickness) and mounted on glass slides for H\&E, and immunostaining. The sections were deparaffinized in xylene, hydrated through graded alcohols, and washed with phosphate buffered saline (PBS). The standard immunohistochemical method was used as previously described [28]. Briefly, endogenous peroxidase blocking was performed using Peroxo-Block ${ }^{\mathrm{TM}}$ (Invitrogen, Life Technologies Ltd, Paisley, UK). Microwave-based antigen retrieval was done with $10 \mathrm{mmol} / \mathrm{l}$ sodium citrate buffer at a $\mathrm{pH}$ of 6.0 , followed by blocking of nonspecific antibody binding with Protein Block serum-free (DAKO, CA, USA). Antihuman TFF1, TFF2, and TFF3 polyclonal antibodies were used as previously described [29-31]. The specificity of the antisera has been tested by lack of cross-reactivity with other family trefoils (both hapten and full-length recombinant protein) in immunoassay, Western blotting, and immunohistochemistry, as well as the same trefoil from other species.

Antihuman TFF1 antibody does not cross-react with human TFF2 or TFF3, nor with mouse or rat TFF1 C-terminal hapten [29]. The anti-human TFF2 antibody cross-reacts with mouse but not rat TFF2, TFF1 or TFF3 [30]. The anti-human TFF3 antibody cross-reacts with all species tested (mouse, rat, human), but not TFF1 nor TFF2 [31]. The optimal dilutions were; 1:400 for antihuman TFF1 and TFF2 antibodies, and 1:800 for TFF3 antibody. Immunodetection system was based on HRP labeled polymer which was conjugated with secondary antibodies (DAKO EnVision+ System-HRP labeled polymer Anti-rabbit). 3,3' diaminobenzidine (DAB) was used as a substrate chromogen (DAKO). The sections were 
counterstained with hematoxylin and then were dehydrated, cleared and mounted. Gastric and colon cancer tissues were used as positive controls, and negative controls were achieved by omitting primary antibodies and substituting with PBS. Upon microscopic examination at original magnification 20X, the whole area of each tissue specimen was selected for analysis of positively immunostained cells. The distributions of positively stained cells in the whole area were evaluated visually by scanning the slide systematically. Assessment of distribution of positively stained cells was inferred to the immunostaining scores as: $0=$ no immunostained cells; $1=$ low distribution (less than $25 \%$ positively stained cells); $2=$ moderate distribution ( $25 \%$ to $50 \%$ positively stained cells); $3=$ high distribution ( $>50 \%$ positively stained cells).

\section{Statistical analysis}

Characteristics of patients with mucocele, benign, and malignant salivary gland tumors were compared using the Chi-square test for categorical variables. The Kruskal-Wallis and Mann-Whitney $U$ tests were performed to analyze differences in TFF immunostaining scores among the comparison groups. To control for the effect of age, multiple linear regression was used to evaluate the association of salivary gland tumors with the levels of TFF expression. Spearman correlation coefficient was performed to determine the correlations between the co-expresion of TFF1/TFF2; TFF1/TFF3; and TFF2/TFF3 in each studied group. In addition, Spearman correlation coefficient was used to evaluate the correlations between TFF immunostaining scores and tumor grading in mucoepidermoid carcinoma cases. The Two-tailed $P<0.05$ was considered statistically significant. 


\section{Results}

\section{Characteristics of tissue specimens}

Demographic characteristics of the investigated specimens are shown in Table 1. The control group was significantly younger $(\mathrm{p}<0.001)$ than those in benign and malignant groups. No differences in age of patients were observed between benign and malignant groups. Although no significant differences in gender were demonstrated among the three groups, females seemed to be predominant in benign and malignant salivary gland tumors within this study. The labial mucosa was the major site for biopsy in the control group, whereas the palate was the major site for biopsy in the benign group. In the malignant group, palate and maxilla were the major sites for biopsy. Most benign and malignant salivary gland tumors were derived from minor salivary glands. Only a few cases were derived from major salivary glands, such as the parotid and sublingual glands. Tumor grading was performed in mucoepidermoid carcinoma cases. There were one case with low grade, 5 cases with intermediate grade, and 5 cases with high grade.

\section{Immunoexpression of TFFs in salivary gland biopsy specimens}

TFF expression in mucocele

Examination of the cellular distribution in mucocele specimens demonstrated that TFF1, TFF2, and TFF3 were present in mucous acini and salivary ducts. TFF immunoexpression was mostly seen in the cytoplasm. Low levels of TFF1, TFF2, and TFF3 were mainly detected in acinar cells, whereas moderate or high levels of TFF1, TFF2, and TFF3 were observed in ductal cells (Figure 1). No staining or low levels of TFF1 and TFF3 were demonstrated in most mucocele specimens with few cases revealing moderate or high expression. More variations in TFF2 expression were observed as compared with TFF1 and TFF3 (Table 2). Co-expression between TFF1/TFF3 was significantly correlated ( $r=0.597$; 
$\mathrm{p}=0.01$ ). In contrast, no significant correlations between TFF1/TFF2 nor TFF2/TFF3 were demonstrated.

TFF expression in benign salivary gland tumors

TFF1, TFF2, and TFF3 expression in pleomorphic adenoma specimens was observed in both non-tumorigenic and tumorigenic areas (Figure 2). In non-tumorigenic areas, low levels of TFF1 and TFF2 and moderate levels of TFF3 were demonstrated in acinar cells, whereas moderate or high levels of TFF1, TFF2, and TFF3 were observed in ductal cells. In tumorigenic areas, high levels of TFF1, TFF2, and TFF3 were observed (Figure 2).

Expression of TFF1, TFF2 and TFF3 was significantly increased in pleomorphic adenoma as compared with the control group $(\mathrm{p}=0.001 ; \mathrm{p}=0.005 ; \mathrm{p}<0.001$, respectively) (Table 2$)$. Coexpression between TFF1/TFF2 was significantly correlated $(\mathrm{r}=0.808 ; \mathrm{p}=0.01)$. In contrast, no significant correlations between TFF1/TFF3 nor TFF2/TFF3 were demonstrated.

TFF expression in malignant salivary gland tumors

All types of malignant salivary gland tumors in this study demonstrated the expression of TFF1, TFF2 and TFF3 (Table 3, Figure 3). More than 70\% of malignant salivary gland tumor specimens demonstrated high expression of TFF1, TFF2, and TFF3 (Table 2). Expression of TFF1, TFF2 and TFF3 was significantly increased in malignant salivary gland tumors as compared with the control group ( $\mathrm{p}<0.001 ; \mathrm{p}<0.001 ; \mathrm{p}<0.001$, respectively) (Table 2). In addition, expression of TFF2 in malignant salivary gland tumors was significantly higher than the benign group $(\mathrm{p}=0.015)$ (Table 2). Co-expression between TFF1/TFF2 $(\mathrm{r}=0.441 ; \mathrm{p}=0.05)$, and TFF2/TFF3 $(\mathrm{r}=0.650 ; \mathrm{p}=0.01)$ was significantly correlated. In contrast, no significant correlations between TFF1/TFF3 were observed. There were no significant correlations between the expression of TFFs and tumor grading in mucoepidermoid carcinoma. 


\section{Discussion}

The present study demonstrated, for the first time, that TFF1, TFF2, and TFF3 were significantly increased in benign and malignant salivary gland tumors. It should be noted that all biopsy specimens in the benign group were pleomorphic adenoma. Thus, obtaining salivary gland tissues from individuals with other benign salivary gland tumors would strengthen an analysis of TFF immunoexpression. Our results are in agreement with previous studies demonstrating overexpression of TFFs in a variety of human cancers [32-36].

However, the present findings are in contrast with our previous observations [18] demonstrating the reduction of TFF2 and TFF3 in oral squamous cell carcinoma (OSCC) lesions of oral mucosa. These findings and the clear inhibition of TFF1 and TFF2 in gastric cancer $[37,38]$, suggest diverse regulation and function of TFF proteins under tumorigenic conditions in different luminal compartments. In the condition of OSCC of oral mucosa which is usually associated with chronic inflammation, it could be postulated that inflammation-mediated signaling transduction such as NFאB signaling pathway might be associated with downregulation of TFF2 and TFF3 [18, 39]. In the condition of salivary gland tumors which is not normally associated with inflammation, it remains unclear which regulatory mechanisms are associated with overexpression of TFFs. It would be of interest to investigate which molecular mechanisms control the expression of TFFs in benign and malignant conditions. On the other hand, it is important to investigate whether overexpression of TFFs could accelerate the rate of neoplastic transformation in salivary gland tissues.

Although the roles of TFFs in tumorigenesis have been investigated intensively, the functional role of TFFs in salivary gland tumors has never been elucidated. Previous studies demonstrated that TFF1 and TFF3 enhanced cell proliferation and promoted cell migration and invasion in mammary carcinoma cell lines [40, 41], whereas TFF2 stimulated cell 
migration and inhibited apoptosis in breast adenocarcinoma cell lines [42, 43]. It has been reported that several salivary gland tumors share similar morphologic features with mammary gland tumors [21-23]. It would be of interest to investigate the functional role of TFFs in salivary gland tumors as compared with the mammary gland tumors in order to evaluate whether TFFs may have context-specific functions in different tissue compartments. According to our observations, the level of TFF2 expression was significantly higher in malignant salivary gland tumors as compared with pleomorphic adenoma. Moreover, coexpression patterns between TFF2 and other TFFs were different between pleomorphic adenoma and malignant salivary gland tumors. These findings suggest that TFF2 may have its own expression profile in response to various pathologic conditions between pleomorphic adenoma and malignant salivary gland tumors. Although pleomorphic adenoma is classified as a benign salivary gland tumor, it has a potential for malignant transformation. Thus, overexpression of TFF2 might be a possible oncogenic factor that enhances malignant transformation in pleomorphic adenoma. However, further studies would be essential to validate the proposed hypothesis.

In the oral cavity, TFFs are mainly produced by salivary glands. Our previous study demonstrated no significant differences in salivary TFF concentrations between OSCC patients and control subjects. These findings imply that production of TFFs by salivary glands is not affected by OSCC lesions of oral mucosa [18]. Based on the present observations, it is tempting to hypothesize that overexpression of TFFs in salivary gland tumors might lead to increased TFF amounts in saliva, and higher levels of salivary TFF concentrations in the patients may be suggestive of salivary gland tumors. In addition, measurements of secreted TFFs in mucosal fluids and serum have been reported for their potential use as diagnostic markers [44]. Thus, quantification of salivary TFF concentrations in patients with oral tumors may be useful for development of biomarkers in terms of 
differential diagnosis between salivary gland tumors and other oral neoplasms which clinical manifestations are indistinguishable. Therefore, further investigations such as comparative studies on the levels of salivary TFF concentrations before and after treatment of patients with salivary gland tumors and other oral neoplasms would help to confirm the clinical significance of TFFs.

In conclusion, the present study provided new information of increased TFF immunoexpression in patients with benign and malignant salivary gland tumors. However, there remain many research gaps in our knowledge about the connection between the functional roles of TFFs and neoplastic transformation in salivary gland tissues. Therefore, intensive studies at a molecular level are needed to clarify regulatory mechanisms for TFF expression in salivary glands under the tumorigenic conditions. In addition, further investigation between overexpression of TFF2 and enhancement of malignant transformation in salivary glands would be of importance. 


\section{Acknowledgements}

This research work was supported by Khon Kaen University, and the National Health and Medical Research Council (NHMRC), Australia. 


\section{Conflicts of Interest Statement}

The authors declare that they have no conflicts of interest. 


\section{References}

1. Kjellev S (2009) The trefoil factor family-small peptides with multiple functionalities. Cell Mol Life Sci 66:1350-69

2. Thim L, May FEB (2005) Structure of mammalian trefoil factors and functional insights. Cell Mol Life Sci 62:2956-73

3. Madsen J, Nielsen O, Tornøe I, Thim L, Holmskov U (2007) Tissue localization of human trefoil factors 1, 2, and 3. J Histochem Cytochem 55:505-13

4. Samson MH, Chaiyarit P, Nortvig H, Vestergaad EM, Ernst E, Nexø E (2011) Trefoil factor family peptides in human saliva and in cyclical cervical mucus. Method evaluation and results on healthy individuals. Clin Chem Lab Med 49:861-8

5. Jagla W, Wiede A, Hinz M, Dietzmann K, Gülicher D, Gerlach KL, Hoffmann W (1999) Secretion of TFF-peptides by human salivary glands. Cell Tissue Res 298:1616

6. Devine DA, High AS, Owen PJ, Poulsom R, Bonass WA (2000) Trefoil factor expression in normal and diseased human salivary glands. Hum Pathol 31:509-15

7. Kouznetsova I, Gerlach KL, Zahl C, Hoffmann W (2010) Expression analysis of human salivary glands by laser microdissection: differences between submandibular and labial glands. Cell Physiol Biochem 26:375-82

8. Kutta H, May J, Jaehne M, Münscher A, Paulsen FP (2006) Antimicrobial defence mechanisms of the human parotid duct. J Anat 208:609-19

9. Storesund T, Schreurs O, Messelt EB, Kolltveit KM, Schenck K (2009) Trefoil factor family 3 expression in the oral cavity. Eur J Oral Sci 117:636-43

10. Chaiyarit P, Chayasadom A, Wara-Aswapati N, Hormdee D, Sittisomwong S, Nakaresisoon S, Samson MH, Pitiphat W, Giraud AS (2012) Trefoil factors in saliva and gingival tissues of patients with chronic periodontitis. J Periodontol 83:1129-38 
11. Storesund T, Hayashi K, Kolltveit KM, Bryne M, Schenck K (2008) Salivary trefoil factor 3 enhances migration of oral keratinocytes. Eur J Oral Sci 116:135-40

12. Storesund T, Schenck K, Osmundsen H, Røed A, Helgeland K, Kolltveit KM (2009) Signal transduction and gene transcription induced by TFF3 in oral keratinocytes. Eur J Oral Sci 117:511-7

13. Perry JK, Kannan N, Grandison PM, Mitchell MD, Lobie PE (2008) Are trefoil factors oncogenic? Trends Endocrinol Metab 19:74-81

14. Emami S, Rodrigues S, Rodrigue CM, Le Floch N, Rivat C, Attoub S, Bruyneel E, Gespach C (2004) Trefoil factor family (TFF) peptides and cancer progression. Peptides 25:885-98.

15. Buache E, Etique N, Alpy F, Stoll I, Muckensturm M, Reina-San-Martin B, Chenard MP, Tomasetto C, Rio MC (2011) Deficiency in trefoil factor 1 (TFF1) increases tumorigenicity of human breast cancer cells and mammary tumor development in TFF1-knockout mice. Oncogene 30:3261-73

16. Yio X, Zhang JY, Babyatsky M, Chen A, Lin J, Fan QX, Werther JL, Itzkowitz S (2005) Trefoil factor family-3 is associated with aggressive behavior of colon cancer cells. Clin Exp Metastasis 22:157-65

17. Vestergaard EM, Nexø E, Tørring N, Borre M, Ørntoft TF, Sørensen KD (2010) Promoter hypomethylation and upregulation of trefoil factors in prostate cancer. Int $\mathbf{J}$ Cancer 127:1857-65

18. Chaiyarit P, Utrawichian A, Leelayuwat C, Vatanasapt P, Chanchareonsook N, Samson MH, Giraud AS (2012) Investigation of trefoil factor expression in saliva and oral mucosal tissues of patients with oral squamous cell carcinoma. Clin Oral Invest $16: 1549-56$

19. Eveson JW (2011) Salivary tumours. Periodontology 2000 57:150-9 
20. Auclair PL, Ellis GL, Gnepp DR, Wenig BM, Janney CG (1991) Salivary gland neoplasms: general considerations. In: Ellis GL, Auclair PL, Gnepp DR (editors) Surgical pathology of the salivary glands, WB Saunders Co, Philadelphia, pp 135-164

21. Camelo-Piragua SI, Habib C, Kanumuri P, Lago CE, Mason HS, Otis CN (2009) Mucoepidermoid carcinoma of the breast shares cytogenetic abnormality with mucoepidermoid carcinoma of the salivary gland: a case report with molecular analysis and review of the literature. Hum Pathol 40:887-92

22. Flynn C, Kadivar M, Kwon MY, Bonzanini M, Haines III GK, Tavassoli FA (2012) Basal cell adenocarcinoma arsing in salivary gland metaplasia of the breast: a novel salivary gland-type tumor developing in the breast. Hum Pathol 43:1764-71

23. Marchio C, Weigelt B, Reis-Filho JS (2010) Adenoid cystic carcinomas of the breast and salivary glands (or 'The strange case of Dr Jekyll and Mr Hyde' of exocrine gland carcinomas). J Clin Pathol 63:220-28

24. Smid M, Wang Y, Klijn JG, Sieuwerts AM, Zhang Y, Atkins D, Martens JW, Foekens JA (2006) Genes associated with breast cancer metastatic to bone. J Clin Oncol 24:2261-7

25. Bosma AJ, Weigelt B, Lambrechts AC, Verhagen OJ, Pruntel R, Hart AA, Rodenhuis S, van 't Veer LJD (2002) Detection of circulationg breast tumor cells by differential expression of marker genes. Clin Cancer Res 8:1871-77

26. Lacroix M (2006) Significance, detection and markers of disseminated breast cancer cells. Endocr Relat Cancer 13:1033-67

27. Eveson JW (2005) WHO histological classification of tumours of the salivary glands. In: Barnes L, Eveson JW, Reichart P, Sidransky D (editors) World Health 
Organization classification of tumours: pathology and genetics of head and neck tumours. IARC Press, Lyon, pp 210

28. Walker RA (2006) Quantification of immunohistochemistry: issues concerning methods, utility and semiquantitative assessment I. Histopathology 49:406-10

29. Srivatsa G, Giraud AS, Ulaganathan M, Yeomans ND, Dow C, Nicoll AJ (2002) Biliary epithelial trefoil peptide expression is increased in biliary diseases. Histopathology 40:261-8

30. Taupin D, Pedersen J, Familari M, Cook G, Yeomans N, Giraud AS (2001) Augmented intestinal trefoil factor (TFF3) and loss of pS2 (TFF1) expression precedes metaplastic differentiation of gastric epithelium. Lab Invest 81:397-408

31. Taupin DR, Pang KC, Green SP, Giraud AS (1995) The trefoil peptides spasmolytic polypeptide and intestinal trefoil factor are major secretory products of the rat gut. Peptides 6:1001-5

32. Poulsom R, Hanby AM, Lalani EN, Hauser F, Hoffmann W, Stamp GW (1997) Intestinal trefoil factor (TFF 3) and pS2 (TFF 1), but not spasmolytic polypeptide (TFF 2) mRNAs are co-expressed in normal, hyperplastic, and neoplastic human breast epithelium. J Pathol 183:30-8

33. Regalo G, Wright NA, Machado JC (2005) Trefoil factors: from ulceration to neoplasia. Cell Mol Life Sci 62:2910-5

34. Dhar DK, Wang TC, Tabara H, Tonomoto Y, Maruyama R, Tachibana M, Kubota H, Nagasue N (2005) Expression of trefoil factor family members correlates with patient prognosis and neoangiogenesis. Clin Cancer Res 11:6472-8 
35. Welter C, Theisinger B, Rio MC, Seitz G, Schüder G, Blin N (1994) Expression pattern of breast-cancer-associated protein $\mathrm{pS} 2 / \mathrm{BCEI}$ in colorectal tumors. Int $\mathrm{J}$ Cancer 56:52-5

36. Luo J, Duggan DJ, Chen Y, Sauvageot J, Ewing CM, Bittner ML, Trent JM, Isaacs WB (2001) Human prostate cancer and benign prostatic hyperplasia: molecular dissection by gene expression profiling. Cancer Res 61:4683-8

37. Peterson A, Menheniott TR, O'Connor LO, Walduck AK, Fox JG, Kawakami K, Minamoto T, Ong EK, Wang TC, Judd LM, Giraud AS (2010) Helicobacter pylori infection methylates and silences TFF2 leading to gastric tumor development in mice and humans. Gastroenterology 139:2005-17

38. Tomita H, Takaishi S, Menheniott TR, Yang X, Shibata W, Betz KS, Kawakami K, Minamoto T, Tomasetto C, Rio MC, Giraud AS, Wang TC (2011) Hormonal inhibition of gastric carcinogenesis is mediated by suppression of epigenetic silencing of TFF1. Gastroenterology 140:879-91

39. Dossinger V, Kayademir T, Blin N, Gött P (2002) Down-regulation of TFF expression in gastrointestinal cell lines by cytokines and nuclear factors. Cell Physiol Biochem 12:197-206

40. Amiry N, Kong X, Muniraj N, Kannan N, Grandison PM, Lin J, Yang Y, Vouyovitch CM, Borges S, Perry JK, Mertani HC, Zhu T, Liu D, Lobie PE (2009) Trefoil factor-1 (TFF1) enhances oncogenicity of mammary carcinoma cells. Endocrinology $150: 4473-83$ 
41. Kannan N, Kang J, Kong X, Tang J, Perry JK, Mohankumar KM, Miller LD, Liu ET, Mertani HC, Zhu T, Grandison PM, Liu DX, Lobie PE (2010) Trefoil factor 3 is oncogenic and mediates anti-estrogen resistance in human mammary carcinoma. Neoplasia 12:1041-53

42. Siu LS, Romanska H, Abel PD, Baus-Loncar M, Kayademir T, Stamp GW, Lalani elN (2004) TFF2 (trefoil family factor2) inhibits apoptosis in breast and colorectal cancer cell lines. Peptides 25:855-63

43. May FE, Semple JI, Prest SJ, Westley BR (2004) Expression and motogenic activity of TFF2 in human breast cancer cells. Peptides 25:865-72

44. Samson MH (2013) Quantitative measurements of trefoil factor family peptides: possibilities and pitfalls. Scand J Clin Lab Invest. doi:10.3109/00365513.2013.765962 
Table 1 Demographic characteristics of the investigated specimens with salivary gland pathology

\begin{tabular}{|c|c|}
\hline & $\underline{\text { a control group }(\mathrm{n}=25)}$ \\
\hline Age (mean, $\pm S D ;$ range $)$ & $26.60 \pm 12.89 ; 10-58$ years \\
\hline Gender (male/female) & $13 / 12$ \\
\hline \multicolumn{2}{|l|}{ Sites of biopsy } \\
\hline labial mucosa & $\mathrm{n}=23$ \\
\hline buccal mucosa & $\mathrm{n}=2$ \\
\hline \multirow{3}{*}{$\begin{array}{l}\text { Type of salivary gland pathology } \\
\text { mucocele }\end{array}$} & \\
\hline & $\mathrm{n}=25$ \\
\hline & a benign group $(n=25)$ \\
\hline Age (mean $\pm S D ;$ range) & $45.36 \pm 20.16 ; 13-83$ years \\
\hline Gender (male/female) & $8 / 17$ \\
\hline \multicolumn{2}{|l|}{ Sites of biopsy } \\
\hline palate & $\mathrm{n}=18$ \\
\hline parotid gland & $n=3$ \\
\hline buccal mucosa & $\mathrm{n}=3$ \\
\hline labial mucosa & $\mathrm{n}=1$ \\
\hline \multicolumn{2}{|l|}{ Type of salivary gland pathology } \\
\hline \multirow[t]{2}{*}{ pleomorphic adenoma } & $\mathrm{n}=25$ \\
\hline & a malignant group $(n=25)$ \\
\hline Age (mean $\pm S D ;$ rangc) & $45.60 \pm 14.33: 18-72$ years \\
\hline Gender (male/female) & $10 / 15$ \\
\hline \multicolumn{2}{|l|}{ Sites of biopsy } \\
\hline palate & $\mathrm{n}=9$ \\
\hline maxilla & $\mathrm{n}=7$ \\
\hline buccal mucosa & $\mathrm{n}=4$ \\
\hline retromolar area of mandible & $\mathrm{n}=2$ \\
\hline sublingual gland & $\mathrm{n}=2$ \\
\hline vestibular area & $\mathrm{n}=1$ \\
\hline \multicolumn{2}{|l|}{ Types of salivary gland pathology } \\
\hline mucoepidermoid carcinoma & $\mathrm{n}=11$ \\
\hline adenoid cystic carcinoma & $n=6$ \\
\hline polymorphous low-grade adenocarcinoma & $\mathrm{n}=4$ \\
\hline acinic cell carcinoma & $\mathrm{n}=3$ \\
\hline basal cell adenocarcinoma & $\mathrm{n}=1$ \\
\hline
\end{tabular}


Table 2 Levels of TFF immunostaining scores in salivary gland biopsy specimens

\begin{tabular}{|c|c|c|c|c|c|c|c|c|c|c|c|c|}
\hline \multirow{3}{*}{$\underline{\text { Salivary gland tissues }}$} & \multicolumn{12}{|c|}{$\underline{\text { TFF immunostaining scores }}^{\mathrm{a}}$} \\
\hline & \multicolumn{4}{|c|}{$\underline{\mathrm{TFF}}^{*}$} & \multicolumn{4}{|c|}{$\underline{\mathrm{TFF}}^{* *}$} & \multicolumn{4}{|c|}{$\underline{\mathrm{TFF}}^{* * * *}$} \\
\hline & $\underline{0}$ & 1 & 2 & 3 & $\underline{0}$ & 1 & 2 & 3 & $\underline{0}$ & 1 & 2 & 3 \\
\hline Control group ${ }^{b}(n=25)$ & 10 & 11 & 3 & 1 & 9 & 6 & 6 & 4 & 10 & 12 & 2 & 1 \\
\hline Benign group ${ }^{c}(n=25)$ & 5 & 4 & 2 & 14 & 1 & 8 & 7 & 9 & - & 5 & 4 & 16 \\
\hline 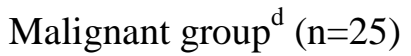 & - & 3 & 4 & 18 & 2 & 2 & 2 & 19 & - & 3 & - & 22 \\
\hline
\end{tabular}

${ }^{\mathrm{a}}$ TFF immunostaining scores were graded as: $0=$ no immunostained cells; $1=$ low distribution (less than $25 \%$ positively stained cells); $2=$ moderate distribution $(25 \%$ to $50 \%$ positively stained cells); $3=$ high distribution ( $>50 \%$ positively stained cells).

${ }^{\mathrm{b}} \mathrm{A}$ control group consisted of 25 cases of mucocele.

${ }^{\mathrm{c}} \mathrm{A}$ benign group consisted of 25 cases of pleomorphic adenoma.

${ }^{\mathrm{d}}$ A malignant group consisted of 11 cases of mucoepidermoid carcinoma; 6 cases of adenoid cystic carcinoma; 4 cases of polymorphous low-grade adenocarcinoma; 3 cases of acinic cell carcinoma; and one case of basal all adenocarcinoma.

*Levels of TFF 1 immunoexpression are significantly increased in benign $(\mathrm{p}=0.001)$ and malignant $(\mathrm{p}<0.001)$ groups as compared with a control group.

** Levels of TFF2 immunoexpression are significantly increased in benign $(p=0.005)$ and malignant $(\mathrm{p}<0.001)$ groups as compared with a control group.

*** Levels of TFF3 immunoexpression are significantly increased in benign $(p<0.001)$ and malignant $(\mathrm{p}<0.001)$ groups as compared with a control group. 
Table 3 Levels of TFF immunostaining scores in malignant salivary gland tumors

\begin{tabular}{|c|c|c|c|c|c|c|c|c|c|c|c|c|}
\hline \multirow{3}{*}{$\underline{\text { Salivary gland tumors }}$} & \multicolumn{12}{|c|}{$\underline{\text { TFF immunostaining scores }}{ }^{\mathrm{a}}$} \\
\hline & \multicolumn{4}{|c|}{$\underline{\mathrm{TFF} 1}$} & \multicolumn{4}{|c|}{$\underline{\text { TFF2 }}$} & \multicolumn{4}{|c|}{$\underline{\mathrm{TFF} 3}$} \\
\hline & $\underline{0}$ & 1 & 2 & 3 & $\underline{0}$ & 1 & 2 & 3 & 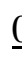 & 1 & $\underline{2}$ & 2 \\
\hline $\begin{array}{l}\text { mucoepidermoid } \\
\text { carcinoma } \\
(\mathrm{n}=11)\end{array}$ & - & 1 & 1 & 9 & 2 & - & 1 & 8 & - & 2 & 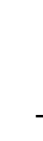 & - \\
\hline $\begin{array}{l}\text { adenoid cystic carcinoma } \\
(\mathrm{n}=6)\end{array}$ & - & 2 & 2 & 2 & - & 1 & 1 & 4 & - & - & - & ( \\
\hline $\begin{array}{l}\text { polymorphous low-grade } \\
\text { adenocarcionma } \\
(\mathrm{n}=4)\end{array}$ & - & - & - & 4 & - & - & - & 4 & 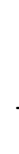 & - & - & 4 \\
\hline $\begin{array}{l}\text { acinic cell carcinoma } \\
(\mathrm{n}=3)\end{array}$ & - & - & 1 & 2 & - & 1 & - & 2 & - & 1 & & 2 \\
\hline $\begin{array}{l}\text { basal cell } \\
\text { adenocarcinoma }(n=1)\end{array}$ & - & - & - & 1 & - & - & - & 1 & - & 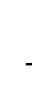 & & -1 \\
\hline
\end{tabular}

${ }^{\mathrm{a}}$ TFF immunostaining scores were graded as: $0=$ no immunostained cells; $1=$ low distribution (less than $25 \%$ positively stained cells); $2=$ moderate distribution ( $25 \%$ to $50 \%$ positively stained cells); $3=$ high distribution ( $>50 \%$ positively stained cells). 


\section{Figure legends}

Figure 1 Immunohistochemical detection of trefoil factors (TFF1, TFF2, and TFF3) in minor salivary glands of specimens diagnosed with mucocele. Immunostaining of TFFs was markedly positive in acinar cells (A) and ductal cells (D).

Expression of TFFs was mostly seen in cytoplasm.

Figure 2 Immunohistochemical examinations of trefoil factors (TFF1, TFF2, and TFF3) in non-tumorigenic and tumorigenic areas of pleomorphic adenoma.

Expression of TFFs was mostly seen in cytoplasm of acinar (A) and ductal (D) cells in non-tumorigenic areas. Increased expression of TFFs was demonstrated in tumorigenic areas of pleomorphic adenoma.

Figure 3 Immunohistochemical examinations of trefoil factors (TFF1, TFF2, and TFF3) in various types of malignant salivary gland tumors including mucoepidermoid carcinoma (MEC); adenoid cystic carcinoma (AdCC); polymorphous low grade adenocarcinoma (PLGA); acinic cell carcinoma (ACC); and basal cell adenocarcinoma (BCAC). Variations in immunoexpression of TFFs were observed in all malignant salivary gland tumors. 

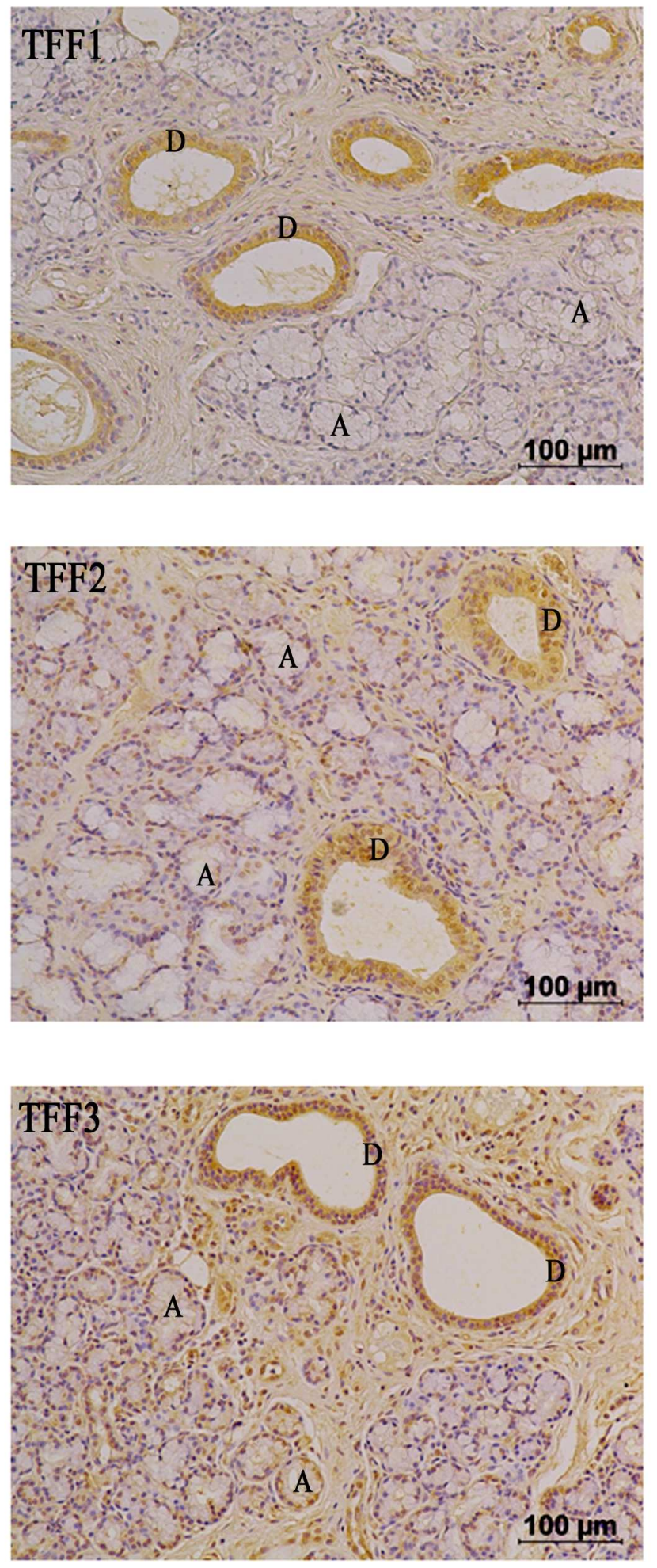
Non-tumorigenic areas
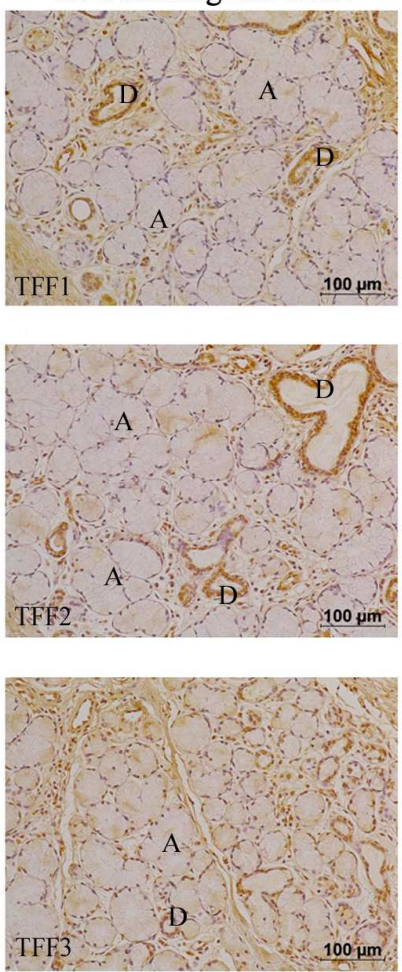

Tumorigenic areas
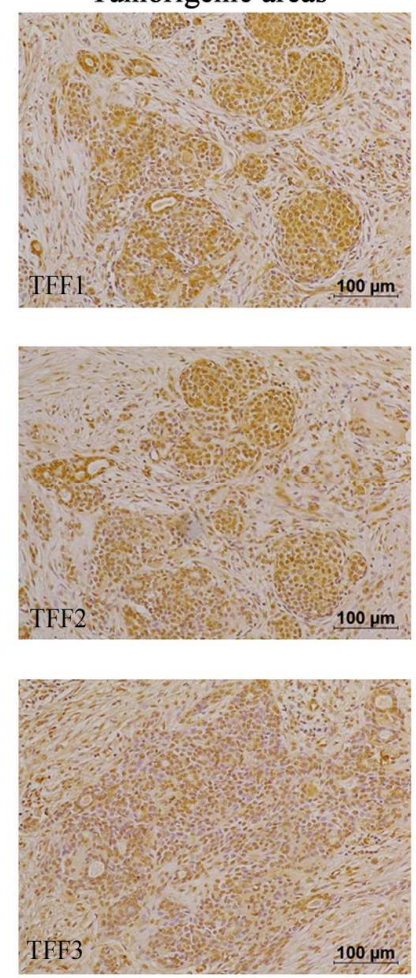
TFF1
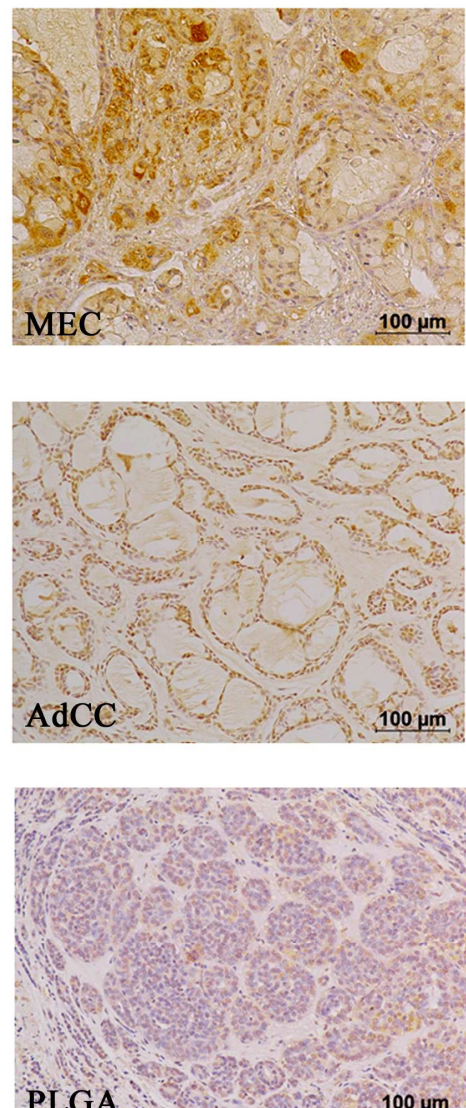

PLGA $\quad 100 \mu$
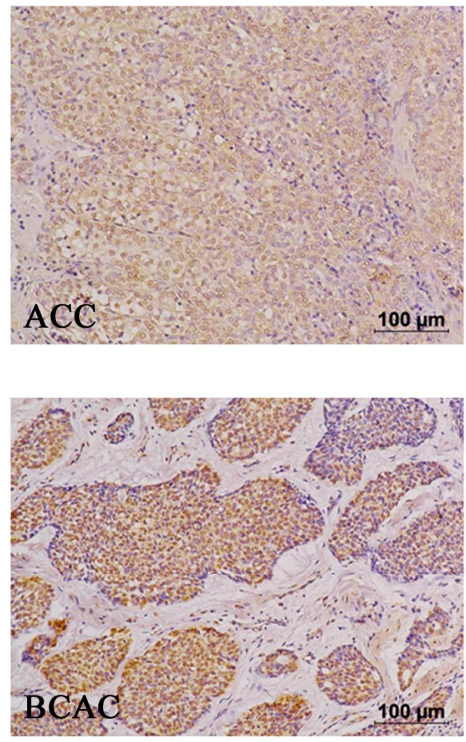

TFF2
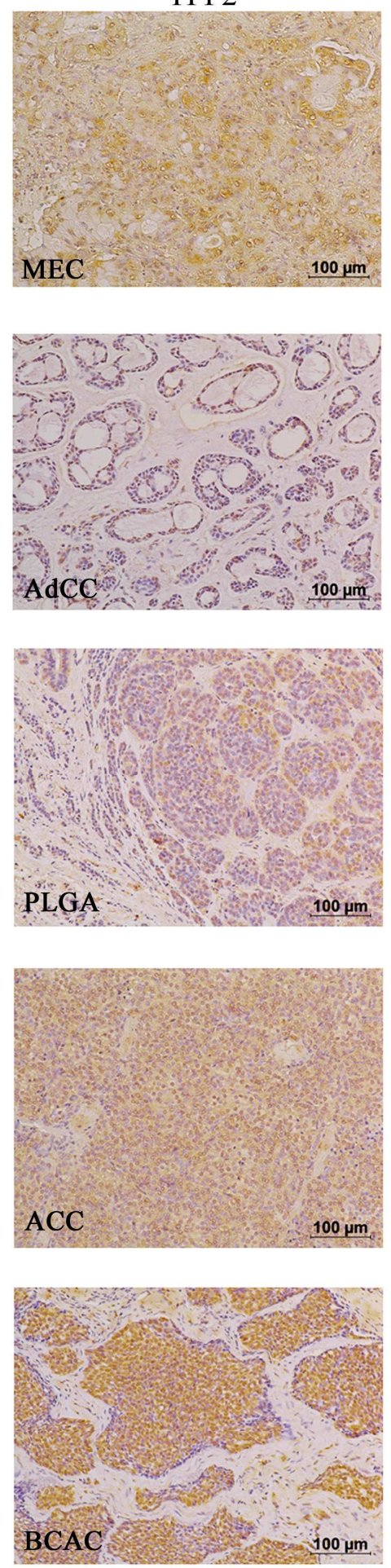

TFF3
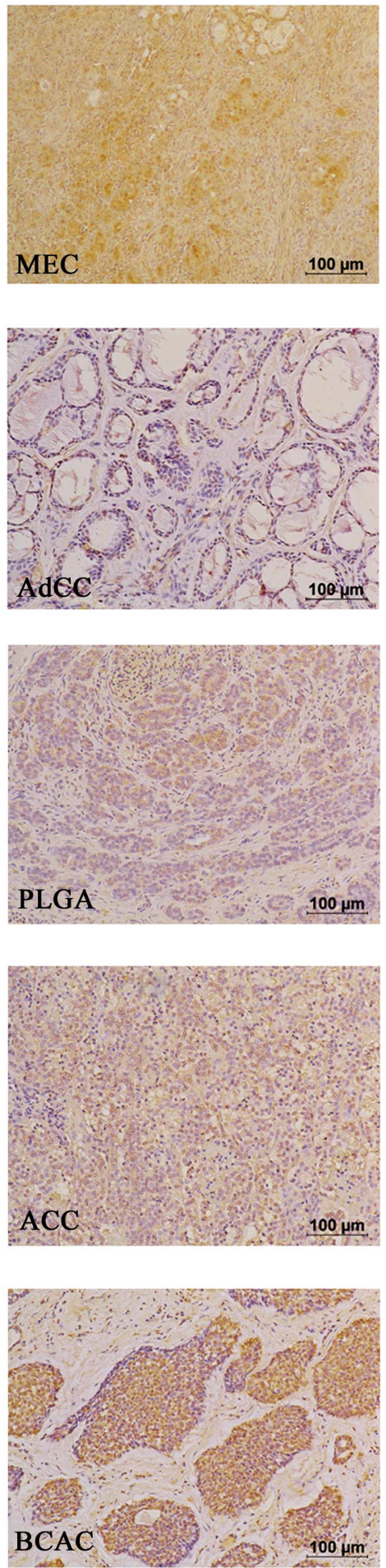